instruct ourselves, to inspire others to act in a way similar to that of the men we revere; perhaps, most of all, to impress the fact of the debt of the living to the past. The continuity of primitive savage instincts in the civilised is a plausible but misleading fallacy in psycho-analysis, and at the best a grave exaggeration. However, in Mr. Trotter's address these allusions only add a quaint flavour of romance. We sympathise with him in his hope that the truly great may be recognised in their lifetime, but we would not have this at the cost of diminishing the respect and remembrance of them after their death. The growth of the latter practice is one of the best features of the age, and offers hope that we may be able to combine our vertiginous progress with the continuity of order.

\section{Third Pedler Lecture of the Chemical Society}

Prof. L. Ruzicka, of Zürich, delivered the third Pedler Lecture to the Chemical Society on March 10, his subject being "The Life and Work of Otto Wallach". Prof. Wallach, whose outstanding contribution to organic chemistry was his pioneer work on the terpene series, was born in Königsberg on March 27, 1847, the son of a Prussian official. His early education was on classical lines, and in addition he had a lifelong interest in the contemplation of art. In 1867 he began his chemical studies in Göttingen under the direction of Wöhler and his assistants, Fittig and Hübner. In the atmosphere of industry which was there cultivated, Wallach obtained his doctor's degree after five semesters of study, his dissertation dealing with position isomerism in the toluene series. After a short period in Berlin as assistant to Wichelhaus, he accepted in 1870 an assistantship at Bonn, offered to him by Kekulé. The period at Bonn, which lasted for nineteen years, was interrupted for a short time when he went to Berlin as the sole chemist to a newly founded enterprise which later developed under the name "Aktiengesellschaft für Anilinfabrikation" (Agfa). In 1889 Wallach was called to Göttingen as successor to Victor Meyer, and retained the direction of the Chemical Institute until 1915. In 1908 he was elected an honorary member of the Chemical Society, and in 1909 received an honorary doctorate of the University of Manchester. The Nobel prize for chemistry was awarded to him in 1910. Wallach died on Feb. 26, 1931, having made such contribution to organic chemistry that any attempt to picture the science with Wallach's work removed would unmistakably disclose a severe gap.

\section{Wallach's Chemical Investigations}

Prof. RuzICKA gave a brief sketch of the principal investigations conducted by Wallach in the domain of terpene chemistry. The work originated in a study of several samples of essential oils which had been kept untouched for fifteen years in a cupboard in Kekulé's private laboratory. It soon became evident that "a great many terpenes formerly designated differently and of supposedly varying constitution are undoubtedly identical". In the first stages several simple reagents were caused to act on the separate fractions of natural terpene mixtures with the view of the separation of crystalline reaction products. In three years Wallach was able to list eight terpenes which obviously differed from one another, each being characterised without ambiguity : pinere, camphene, limonene, dipentene, sylvestrene, terpinolene, terpinene, and phellandrene. Later it appeared that dipentene is $d l$-limonene, and that pinene, terpinene, and phellandrene are mixtures of $\alpha$ - and $\beta$-compounds ; moreover, it is now known that sylvestrene does not occur in Nature. Wallach also investigated oxy. genated terpene derivatives and the sesquiterpenes, particularly cadinene and caryophyliene. After characterisation of the individual terpenes, he considered the elucidation of their innumerable mutual relations to be more important than the determination of their constitution. The real harvest from the persistent work of Wallach was reaped in 1895, when, with a single stroke, the structure of an entire series of terpene compounds was elucidated. With the end, about this time, of the heroic period in terpene chem. istry, Wallach ceased to play the part of pioneer. Of his later work, Prof. Ruzicka referred to that on bicyclic representatives of the terpene series, and that concerned with simple alicyclic compounds.

\section{Early History of Magnetism}

AT a meeting of the Newcomen Society held at the British Industries Fair, Birmingham, on March 2, Dr. J. B. Kramer read a paper on " The Early History of Magnetism ", in which he discussed the various accounts of the first discovery of a magnet, and the development of the science of magnetism down to A.D. 1600. His remarks were divided into five sections, the first dealing with the discovery of magnetism up to and including the writings of Lucretius, about 95-52 B.c.; the second with the interpretations and first applications of magnetism up to the thirteenth century; the third with the experimental researches of Peter Peregrinus of Marincourt, A.D. 1269; the fourth with the magnetic compass, between the thirteenth and sixteenth centuries; and the last with the discovery of terrestrial magnetism by Gilbert, and with Gilbert's book, "De Magnete".

\section{Discovery of Magnetic Properties}

For the claim that is sometimes made that the magnet was first known to the Chinese, Dr. Kramer finds no support, but after examining the works of Aristotle and others, he comes to the conclusion that the magnet was discovered accidentally by one of the Grecian tribes who originally inhabited Thessaly and were called Magnetes. The discovery was made in one of the settlements in Asia Minor, in the Province of Lydia, about 600 B.c. That magnets attract through a distance, that they induce magnetism in iron, and that they repel as well as attract, are mentioned by Lucretius. Who made the great discovery that if allowed to move freely a magnet pointed north and south is not known, but Peter Peregrinus describes the dual polarity of magnets. The work of Gilbert was based on 199 'magnetical

No. 3255 , Vou. 129] 
experiments', and his greatest original contribution to science was his magnificent discovery and proof that the earth is a colossal natural magnet in itself. Dr. Kramer's paper contains many extracts from the various writers on magnetism, and should prove of wide interest.

\section{Goethe's Scientific Works}

A special issue of the Berlin journal, Forschungen und Fortschritte, dated March 1932, includes thirtynine pages devoted to a series of articles by more than thirty authorities dealing chiefly with Goothe's influence as a man of science. The subjects covered include mathematics, the theory of colours and optics, chemistry, geology, meteorology, botany, zoology, and anatomy, together with an appreciation of the Goethe Museum at Frankfurt. In the restricted space at the disposal of each author, it has only been possible to deal very briefly with what are often abstruse and involved matters of history, but, nevertheless, these articles should prove a very useful guide to those who propose to take up the study of Goethe's scientific works. The modern critic of Goethe's central idea of the unity of plan has little to add to Schiller's acute observation of 1794, quoted by Prof. O. Abel-_" Das ist keine Erfahrung, das ist eine Idee ", and Goethe's response- - "Das kann mir sehr lieb sein, dass ich Ideen habe, ohne es zu wissen, und sie sogar mit eigenen Augen sehe ", is an admirable epitome of his own attitude towards the central idea.

\section{Source of 'Nagana' in South Africa}

Dr. E. WARren, director of the Natal Museum, has reported, according to a message in the Times of March 10, that experiments carried out by $\mathrm{Mr}$. Davidson, an independent naturalist, " completely destroy the theory at present accepted about the reservoir of infection from which the tsetse fly transmits the widespread cattle disease known as Nagana". It is generally accepted-and has, in fact, been repeatedly proved-that the blood of game animals harbours trypanosomes which, when conveyed to domestic animals by the tsetse fly, give rise to the serious and often fatal diseases which are grouped under the term 'nagana'. Mr. Davidson now claims to have shown that the trypanosome responsible is derived from the latex of certain plants " on which the tsetse fly normally feeds ". Further information on these observations (which appear to have satisfied Dr. Warren, by whom they have been " carefully checked") will be awaited with much interest. It is well known that leptomonad-like flagellates are common in the latex of Euphorbia and other plants, being transmitted from one plant to another by certain plant-sucking bugs; but no evidence has as yet been published that these organisms can cause disease in vertebrates; and up to the present time no trypanosome has ever been discovered in a plant. The tsetse fly has occasionally been observed to plunge its proboscis into certain fruits, but in the past it has seemed very doubtful if these constitute a regular source of food supply.

No. 3255, VoL. 129]

\section{Chester Roman Amphitheatre Appeal}

DeTERMINed efforts are to be made to save the Roman amphitheatre at Chester, which is threatened by the proposal to construct a by-pass road that, on the lines contemplated at present, would pass through the centre of the arena. The Council of the Chester and North Wales Archæological Society has issued a statement in which it is pointed out that even if the road could be constructed without damage to the remains, which is doubtful, it would put excavation in the future out of the question, while it is inevitable that the northern area adjoining the road would be developed for building purposes, and also made inaccessible. The Office of Works, which has been approached in the matter, views with approval the scheme to save the amphitheatre, which is the most considerable in Great Britain. The Office of Works would itself undertake the cost of excavation and be responsible for the future maintenance of the monument if the site was placed in its keeping. The cost of diverting the by-pass road to avoid the amphitheatre is estimated at a sum of $£ 8000$. The Council of the Archæological Society, therefore, appeals to the people of Chester, and of Great Britain, for a sum sufficient to enable this monument to be preserved. A stay of three months has been granted to afford an opportunity for the amount required to be raised.

\section{Metallurgical Literature}

THE annual general meeting of the Institute of Metals was held on March 9 and 10, and the incoming president, Sir Henry Fowler, delivered his addresis on the first day. Referring to the literature of metallurgy forty years ago, Sir Henry remarked that it was very meagre in Great Britain, especially as regards nonferrous metals; and that possibly this lack was in part responsible for the formation of the Institute of Metals, for among its original objects was the publication of a journal containing original papers and abstracts. Abstracts appeared for the first time in the second volume of the Journal of the Institute, occupying 41 pages. In the last issue of the Journal in which they were incorporated, they occupied (with index) 436 pages. Now that the Journal is being published monthly, it is hoped that abstracts will be available within six weeks of the original publication of important papers. Sir Henry stated that more than a thousand periodicals, in about twenty languages, are searched systematically by a band of more than thirty qualified abstractors, who provided in the past twelve months more than four thousand abstracts. The magnitude of this undertaking is probably unique as the work of a single institution.

\section{Practical Applications of Fundamental Research}

Sir Henry Fowler went on to speak of the importance of fundamental research and of the 'marrying-up' of research with its practical applications. There is nowadays unquestionably much better understanding between the research worker in metallurgy and the practical engineer, due to the 